\title{
Conflito Conjugal: Impacto no Desenvolvimento Psicológico da Criança e do Adolescente
}

\author{
Marital Conflict: Impact on the Psychological Development \\ of Children and Adolescents
}

\author{
Silvia Pereira da Cruz Benetti * \\ Universidade do Vale do Rio dos Sinos, São Leopoldo, Brasil
}

\begin{abstract}
Resumo
As investigações sobre os processos relacionais familiares indicam uma associação entre conflito conjugal e presença de adversidade no contexto familiar com implicações no desenvolvimento psicológico de crianças e adolescentes. Este artigo propõe-se a revisar algumas contribuições teóricas importantes sobre o tema, abordando alguns resultados das pesquisas sobre o impacto do conflito conjugal no desenvolvimento psicológico de crianças e adolescentes. Discute-se, também, a contribuição do modelo cognitivo-contextual e do modelo segurança-emocional na compreensão das relações familiares e do conflito conjugal. Finalmente, são abordadas as implicações teóricas e práticas para as pesquisas na área da psicologia.

Palavras-chave: Conflito conjugal; crianças; adolescentes; desenvolvimento psicológico; relações familiares.

Abstract

The investigations about family relations indicate an association between marital conflict and the presence of adversity in the family context with consequences on the psychological development of children and adolescents. The purpose of this article is to review some of the theoretical contributions on the subject, including some results of researches on the impact of marital conflict on the psychological development of children and adolescents. Also, the contributions of the cognitive-contextual model and the emotional-security model for the comprehension of family relations and marital conflict are discussed. Finally, theoretical and practical consequences for research in the psychological field are discussed.

Keywords: Marital conflict; children; adolescents; psychological development; family relations.
\end{abstract}

Estudos sobre os processos familiares indicam que a qualidade da relação parental e a presença de discórdia no ambiente familiar são fatores associados à etiologia de distúrbios emocionais na criança e no adolescente (Cummings \& Davies, 2002; Wamboldt \& Wamboldt, 2000). Primeiramente, identificou-se uma associação geral entre discórdia conjugal e dificuldades no ajustamento infantil, considerando-se que as situações de conflito conjugal na família resultavam numa alteração das práticas educativas parentais que, por sua vez, interferiam no desenvolvimento da criança. Posteriormente, verificou-se que determinadas características das situações de conflito estavam diretamente relacionadas ao desenvolvimento da criança (Fincham, 1994, 2003). Além disto, os efeitos do conflito conjugal eram principalmente determinados pela exposição da criança/adolescente a episódios de discórdia familiares e não somente a uma al teração das práticas educativas por parte dos pais (Zeanah \& Scheeringa, 1997).

A questão do impacto do conflito conjugal nos processos psicológicos, cognitivos e relacionais da criança e do adolescente surgiu com maior ênfase recentemente, a partir da constatação de que a presença de conflitos estava

*Endereço para correspondência: Curso de Psicologia, Universidade do Vale do Rio dos Sinos, UNISINOS Av. UNISINOS, 950, São Leopoldo, RS. E-mail: silvia1@net.crea-rs.org.br associada a uma maior exposição da criança a situações de estresse familiar. Determinados padrões de interação conjugal, principalmente aqueles associados com maior adversidade e violência, foram relacionados a distúrbios no desenvolvimento emocional, cognitivo, social e até a alterações psicofisiológicas na criança (El-Sheikh \& Harger, 2001). Como consequiência, a dimensão conflito conjugal assumiu um papel de grande relevância nas investigações sobre as relações familiares, ao ponto de inclusive questionar o entendimento do divórcio parental como gerador de distúrbios no desenvolvimento da criança e do adolescente. Ao contrário, considerou-se que a presença de distúrbios emocionais na criança não estava relacionada unicamente à situação do divórcio parental, mas, sim, à exposição da criança a conflitos intensos anteriores ao rompimento familiar (Fonagy, Target, Steele \& Steele, 1997). Apesar dos estudos sobre o tema situarem-se no período das duas últimas décadas, a contribuição dos achados dos principais trabalhos de pesquisa já se constitui num expressivo corpo teórico sobre as relações familiares e as conseqüências do conflito parental no desenvolvimento infantil. Atualmente, a dimensão conflito conjugal é considerada como um processo familiar impor tante para ocorrência de distúrbios afetivos e manifestações clínicas no desenvolvimento infantil (Wamboldt \& Wamboldt, 2000; Zeanah \& Scheeringa, 1997) e com posteriores dificuldades na adolescência, como agressividade, conduta anti-so- 
cial, abuso de substância e envolvimento com a lei (Fergusson \& Horwood, 1998).

O presente artigo tem como objetivo apresentar os achados de algumas pesquisas sobre as associações entre as relações familiares e o desenvolvimento psicológico da criança, abordando, especificamente, a questão dos efeitos do conflito conjugal na psicopatologia infantil. Para tal, serão revisadas as principais contribuições sobre o tema e os modelos explicativos sobre as relações associativas e processos psicológicos subjacentes à ocorrência de conflitos conjugais durante o processo de desenvolvimento da criança. Na primeira parte do trabalho serão destacados os componentes mais importantes dos processos relacionais envolvidos na conflitiva familiar. A seguir, serão discutidas as propostas explicativas baseadas no modelo cognitivo-contextual (Grych \& Fincham, 1990) e no modelo segurança-emocional (Davies \& Cummings, 1994). Ao final, serão feitas algumas considerações em relação à implicação dos achados para a pesquisa em psicopatologia do desenvolvimento.

\section{Estudos Iniciais sobre Discórdia Familiar e o Conflito Conjugal}

Segundo Cummings e Davies (2002), a primeira geração de pesquisas sobre os efeitos do conflito conjugal no desenvolvimento psicológico da criança teve o importante papel de apontar a associação entre a discórdia parental e a presença de adversidade no contexto familiar. Esta situação se caracterizaria por uma maior vulnerabilidade emocional no sistema intrafamiliar (Emery \& O’Leary, 1982) estando a ocorrência de conflito conjugal na família relacionada à psicopatologia infantil, principalmente desordens de interiorização (Johnston, Gonzalez \& Campbell, 1987) e de exteriorização (Jouriles, Murphy \& O’Leary, 1989), e a aspectos mais amplos da dinâmica das relações familiares, como a associação entre conflito conjugal e depressão materna (Cummings \& Davies, 1994), alcoolismo, abuso físico e sexual.

Katz e Gottman (1993) descreveram os trabalhos iniciais sobre as características das relações conjugais e o desenvolvimento infantil como limitados à investigação da qualidade da relação parental utilizando-se da noção de satisfação pessoal no relacionamento do casal como referência para o estudo das situações familiares de discórdia. Esses trabalhos tinham como foco de investigação o nível de satisfação/insatisfação do casal no relacionamento conjugal e sua relação com o comportamento infantil, sendo a insatisfação conjugal apontada como relacionada à qualidade do desenvolvimento infantil. Apesar da importante contribuição desses estudos sobre a relação entre insatisfação na relação conjugal e a presença de indicadores negativos no desenvolvimento da criança, não foram identificados quais aspectos específicos do processo familiar estavam relacionados aos distúrbios infantis. Isto é, nem todo o relacionamento conjugal insatisfatório implicava em dificuldades no desenvolvimento da criança e nem apresentava disputas ou estratégias idênticas na resolução dos conflitos. Havia uma grande variabilidade nos padrões de interação conjugal na presença de conflitos, incluindo situações nas quais os conflitos eram encobertos, até àquelas envolvendo violência física entre o casal.

Desta forma, Fincham (1994) argumentou que os estudos iniciais permitiram uma gradual diferenciação da dinâmica familiar, primeiro identificando a associação entre a satisfação e o nível de concordância entre o casal e características do desenvolvimento infantil. Passou-se, a seguir, a determinar a influência específica da dimensão conflito conjugal e, posteriormente, a apontar algumas características do conflito conjugal como mais relevantes e determinantes para aspectos negativos do desenvolvimento psicológico em geral. Outro aspecto importante foi a verificação de que a variabilidade encontrada nas correlações entre o conflito conjugal e distúrbios na criança justificava um questionamento mais crítico do fenômeno com relação à metodologia das investigações, especialmente na necessidade de definições mais específicas do constructo teórico conflito conjugal.

A segunda geração de pesquisas, surgida na úl tima década, tinha como objetivo a identificação dos processos subjacentes aos efeitos do conflito conjugal na família procurando, de forma mais específica, compreender como as crianças são afetadas pelas situações de conflito intrafamiliar. Esse esforço de entendimento fundamentou-se num modelo compreensivo mais complexo das interações entre os diversos fatores e influências no contexto familiar, procurando discriminar quais características das interações conjugais e, principalmente, das interações pais e filhos nos sistemas familiares afetavam o desenvolvimento da criança e do adolescente (Cummings \& Davies, 2002). Entretanto, a diversidade entre as correlações encontradas (.25-.40), bem como a constatação de que amostras clínicas evidenciavam associações mais significativas do que estudos não clínicos, levou os pesquisadores a postularem modelos explicativos mais complexos sobre a relação entre conflito e impacto no desenvolvimento infantil (Fincham, 1994). Assim, verificou-se que os diferentes padrões de conflito conjugal refletiam não somente as características da interação entre o casal, mas também eram influenciados por questões mais amplas da vida relacional familiar, afetando de forma diferenciada o desenvolvimento infantil. Passou-se, então, de uma análise unidimensional do conflito familiar para uma compreensão multidimensional dos processos familiares envolvidos nos conflitos conjugais e das conseqüências para o desenvolvimento da criança (Katz \& Gottman, 1993), bem como a consideração das circunstâncias promotoras de crescimento psicológico e as características de resiliência da criança.

\section{Aspectos Multidimensionais do Conflito Conjugal}

Situações de discórdia entre o casal, manifestadas na forma de conflito conjugal, podem caracterizar-se por diferentes níveis de intensidade, freqüência, conteúdo e resolução, além de serem expressas no cotidiano familiar 
Benetti, S.P.C. (2006). Conflito Conjugal: Impacto no Desenvolvimento Psicológico da Criança e do Adolescente.

de forma aberta ou encoberta. Considera-se que todo o sistema familiar envolve certo nível de conflito, sendo inclusive um aspecto positivo no processo de desenvolvimento psicológico infantil a observação de que adultos podem discordar e encontrar, de alguma forma, uma maneira de resolver suas dificuldades. Dessa forma, o primeiro ponto a ser destacado no construto multidimensional do conflito conjugal é identificar quais aspectos exercem um efeito disruptivo no processo de desenvolvimento infantil. Igualmente, são importantes as questões de quais aspectos do desenvolvimento infantil são afetados pela presença de conflito conjugal, considerando-se a adaptação geral da criança, o desenvolvimento emocional, cognitivo e a esfera comportamental (Cummings, 1998).

As dimensões mais importantes do conflito conjugal, entendido como um construto inter-relacionado e composto de diferentes situações particulares a cada caso, são a freqüência da ocorrência de interações conflitivas entre o casal, a intensidade das interações, o conteúdo sobre o que está ocasionando o conflito e, finalmente, a forma como as interações conflitivas são resolvidas (Grych \& Fincham, 1990).

\section{Freqüência}

A exposição da criança a episódios freqüentes de disputa entre o casal, ou seja, a ocorrência de episódios constantes de conflito conjugal como forma de relacionamento familiar é um fator determinante de estresse. Conflitos freqüentes geram respostas emocionais intensas por parte da criança, que podem manifestar-se por meio de condutas agressivas ou depressivas (Dadds, Sanders, Morrison \& Rebgetz, 1992). Crianças expostas a situações de conflito conjugal apresentam maior incidência de sintomas de ansiedade, agressividade, distúrbio de conduta (Jenkins \& Smith, 1991) e depressão (Katz \& Gottman, 1993).

\section{Intensidade}

A intensidade da expressão dos conflitos é variada. Pode se caracterizar por situações de calma disputa entre o casal, até episódios envolvendo agressão e violência verbal, emocional ou física. Apesar da evidência de que a exposição à violência física causa maior dano psicológico à criança (Zavaschi, Benetti, Polanczyk, Solés \& Sanchotene, 2002), episódios de agressões verbais e emocionais têm efeitos tão negativos quanto os físicos e foram relacionados à ocorrência tanto de problemas de interiorização como exteriorização (Grych \& Fincham, 1990). Também a intensidade dos episódios de conflito entre o casal está associada a uma maior freqüência das situações de conflito.

\section{Tópico}

O tópico ou razão do conflito tem sido igualmente associado como outra fonte de estresse para a criança, já que muitas vezes os conflitos tratam de situações relacionadas à própria criança, tais como questões de manejo e supervisão nas quais os pais divergem sobre suas opiniões ou condutas, provocando intensa ansiedade infantil (Cummings, 1998). Segundo Hetherington e Stanley-
Hagan (1999), a habilidade dos pais em proteger a criança da exposição a conflitos e do estabelecimento de alianças baseadas em hostilidade contra um dos pais evita que esta fique numa posição intermediária da disputa.

\section{Resolução}

As situações nas quais os conflitos são resolvidos de forma satisfatória entre o casal não possuem necessariamente características tão negativas e, ao contrário, muitas vezes geram importantes processos de amadurecimento emocional e cognitivo na criança, em função de que promovem discussões menos coercivas, agressivas e com menor ataque verbal ao companheiro (Cummings, 1998; Grych \& Fincham, 1990). No sentido oposto, certos padrões negativos de resolução de conflitos podem provocar efeitos adversos. Katz e Gottman (1993) mencionam os padrões de (a) exigência x evitação e de (b) mútua hostilidade contínua, como formas predominantes de dificuldades na resolução de conflitos. No primeiro caso, um elemento do casal procura alcançar a mudança no companheiro por meio de críticas, exigências e demandas intensas, provocando a retração e desinteresse do outro parceiro, que passa a evitar a situação, calar-se ou deixar de exibir qualquer forma de interação - padrão de demanda e de abandono. No segundo caso, críticas, manifestações de afeto negativo, utilização de ironia e de comentários depreciativos dirigidos ao parceiro assumem um padrão constante, caracterizado por mútua hostilidade contínua entre o casal.

A resolução de conflitos familiares de forma agressiva é vivida pela criança como experiência cotidiana de violência, indicando que a solução de problemas pode ser alcançada através do uso de estratégias agressivas. $\mathrm{Na}$ investigação de Lisboa et al. (2002), crianças vítimas de violência familiar utilizavam-se de comportamentos agressivos nas estratégias de enfrentamento de conflitos com os colegas, indicando que o padrão familiar agressivo na resolução dos conflitos era transposto para o convívio social.

\section{Outros aspectos}

Características como gênero, idade da criança e procedência das amostras estudadas (clínicas e não clínicas) têm apontado tendências variadas nas análises sobre a interrelação entre essas características e os padrões de conflito conjugal. No caso do gênero, meninos apresentam, em algumas investigações, uma maior tendência a manifestar distúrbios de conduta e agressividade do que meninas, que teriam uma maior tendência a condutas e afetos depressivos (Fincham, 1994). Entretanto, há variabilidade nesses achados em função das distintas avaliações do constructo conflito conjugal (Grych \& Fincham, 1990). Já as amostragens clínicas tendem a apresentar correlações mais robustas entre conflito conjugal e distúrbios na criança. Porém, a ocorrência de outros fatores afetando famílias em atendimento clínico justifica uma análise mais cautelosa (Jouriles, Murphy \& O'Leary, 1989).

Como pôde ser visto, a abordagem do constructo conflito conjugal está baseada numa compreensão multidimensional que envolve as características de freqüência dos 
conflitos, da intensidade, do conteúdo e da forma como são resolvidas as situações de discórdia. Considera-se que a presença de conflitos no funcionamento familiar, por si só, não está necessariamente associada a dificuldades no ajustamento da criança e adolescente, dependendo de aspectos específicos de cada dimensão. Além disto, algumas condutas parentais face ao conflito têm função construtiva no amadurecimento emocional da criança. Tais situações compreendem ações que evidenciam esforços de resolução de conflitos, procura de alternativas e explicações sobre os acontecimentos à criança, indicando a perspectiva de que dificuldades são situações que devem ser trabalhadas e discutidas.

Ao contrário, condutas destrutivas envolvem agressão interpessoal e violência, conflitos não verbais com distanciamento afetivo parental durante o episódio, agressão física, agressão a objetos, ameaças à integridade da família e conflitos envolvendo a criança (Cummings \& Davies, 2002). Esses casos, principalmente aqueles envolvendo violência conjugal, originam situações adversas que interferem nas relações parentais e nas práticas de socialização da criança. A seguir, serão abordadas as contribuições sobre as associações entre conflito conjugal e as relações parentais, com ênfase nas situações de violência conjugal.

\section{Conflito Conjugal e as Relações Parentais}

As relações entre pais e filhos são fundamentais no processo de desenvolvimento, porém, o sistema familiar como um todo constitui um contexto relacional importante para o desenvolvimento da criança e do adolescente (Cummings \& O’Reilly, 1997). Segundo Holden, Geffner e Jourieles (1998), faz-se necessário a inclusão do sistema familiar, principalmente das características das relações conjugais, nos modelos conceituais do desenvolvimento psicológico da criança. Partindo do modelo de Belsky (1984), no qual as relações entre pais e filhos são afetadas (a) pela personalidade dos pais e experiência emocional de bem-estar, (b) pelas características da própria criança, e (c) pelas fontes ambientais e contextuais de estresse, Holden, Geffner e Jourieles consideram necessária a inclusão no modelo do fator relação conjugal. Isto porque as características da relação conjugal influenciam diretamente a disponibilidade afetiva e física dos pais no cuidado e no envolvimento com os filhos e, em geral, os conflitos entre o casal ocasionam uma deterioração dessas relações entre pais e filhos (Grych \& Fincham, 1990).

Cummings e O'Reilly (1997) argumentam que a qualidade da relação do casal está relacionada com maior disponibilidade, tanto materna quanto paterna, no envolvimento com os filhos. Casais que consideram as relações conjugais como satisfatórias apresentam envolvimento similar e equivalente com os filhos. Ao contrário, dificuldades na relação do casal diminuem o envolvimento e a disponibilidade parental, principalmente a disponibilidade paterna. Em geral, a relação mãe-filhos tende a manter-se mais estável do que a relação pais-filhos face à presença de conflitos conjugais. Dessa forma, o impacto do conflito conjugal tem um caráter mais negativo na disponibilidade afetiva e no envolvimento masculino, tendo sido observado menor interesse paterno pelos filhos e participação em geral na família em situações de conflito conjugal.

Entretanto, alguns estudos também identificam alterações na disponibilidade materna, visto que o conflito conjugal estava associado à maior ocorrência de depressão nas mães (Coyne, Thompson \& Palmer, 2002; Downey \& Cowney, 1990). No estudo de Coyne, Thompson e Palmer casais com mulheres deprimidas apresentavam maiores dificuldades conjugais, menor expressão afetiva e presença de táticas mais destrutivas na resolução dos conflitos. Segundo Cummings (1995) e Downey e Cowney (1990), as dificuldades de comportamento e desenvolvimento psicológico da criança com pais depressivos resulta do clima de discórdia e de conflito da relação parental, mais do que a ocorrência da patologia nos pais.

Por sua vez, Oliveira et al. (2002) em uma investigação sobre os estilos parentais intergeracionais, conflito conjugal e comportamentos de internalização e de externalização infantil identificaram que a conflitiva conjugal mediava as situações de estilo materno autoritário. A atitude conjugal conflituosa materna associava-se ao estilo autoritário da mãe e constituía um fator de risco para comportamentos de externalização.

Além de afetar a disponibilidade parental para com os filhos, a exposição aos episódios de conflito conjugal gera estados afetivos internos na criança de intenso sofrimento psíquico e estresse e alterações emocionais e fisiológicas (El-Sheik \& Harger, 2001). Há um esforço, por parte da criança, de controlar ou regular as relações parentais disfuncionais, numa tentativa de diminuir a tensão familiar. Entretanto, essas situações são dificilmente resolvidas a partir destas estratégias, tendo como resultado a organização de representações do self e dos relacionamentos com adultos de forma agressiva e negativa. Neste sentido, Santos e Costa (2004) salientam que os efeitos da dinâmica conjugal violenta sobre o desenvolvimento dos filhos associam-se à posição ambivalente da criança ao se deparar com a conflitiva dos pais. Isto porque a aliança e a lealdade para com os pais colocam a criança numa situação de opção entre defender o agressor ou a vítima, ocasionando divisões internas no funcionamento familiar. Além disto, a própria criança se depara com a tarefa de conciliar o amor pelo genitor violento e a raiva pela situação vivida na família.

Dentre todas as situações que afetam o sistema familiar, a ocorrência de conflito conjugal associada a episódios de violência entre o casal, constitui-se em uma das formas mais negativas de interação e expressão afetiva, com graves conseqüências para o desenvolvimento infantil.

\section{Conflito Conjugal e Violência Familiar}

A comorbidade entre conflito conjugal e violência familiar é outro aspecto adverso identificado nos estudos sobre violência que aumenta as chances de ocorrência de 
Benetti, S.P.C. (2006). Conflito Conjugal: Impacto no Desenvolvimento Psicológico da Criança e do Adolescente.

episódios de maus-tratos dirigidos à criança (Ross, 1996). Conflito conjugal está presente em casos de abuso, negligência infantil, e violência familiar (Jouriles et al., 1989). A deterioração da relação conjugal pode levar à reprodução de práticas abusivas na relação entre pais e filhos e a práticas disciplinares inconsistentes. Muitas vezes as crianças, além de testemunharem o conflito entre os pais, também são vítimas do mesmo (Wolfe, 1999; McCloskey, Figueredo \& Koss, 1995). Ainda que episódios de maustratos infantis sejam indubitavelmente traumáticos, a mera exposição da criança à violência, especialmente a episódios de agressão física entre o casal, provoca danos psicológicos importantes no processo de desenvolvimento infantil, com seqüelas duradouras no amadurecimento da personalidade em geral (Cummings, 1998; Katz \& Gottman, 1993). Nesse sentido, dois aspectos são considerados como associados ao dano psicológico à criança: um deles é quando a criança é exposta às situações de conflitos intensos entre os pais envolvendo violência física (Jouriles et al., 1989), o outro é quando a própria criança passa a ser também vítima das agressões parentais, caso que se caracterizaria como de abuso verbal ou físico.

Alguns autores, entretanto, consideram que, apesar da evidência de que a presença de violência física causa maior dano psicológico à criança, agressões verbais e emocionais ocasionam conseqüências tão negativas quanto as físicas (Grych \& Fincham, 1990). Na investigação de Fantuzzo et al. (1991) com 107 crianças pré-escolares, o grupo de crianças exposto somente a episódios de conflito verbal apresentou níveis moderados de distúrbio de conduta. Já o grupo de crianças exposto ao conflito verbal e físico tinha níveis clínicos de distúrbio de conduta e um nível moderado de distúrbio emocional. O grupo exposto a conflito verbal, físico e residindo em abrigos apresentou níveis clínicos de distúrbio de conduta, altos níveis de distúrbio emocional e baixo nível de adaptação social.

Estudos longitudinais apontam que os efeitos da exposição à violência conjugal na infância persistem na juventude. Fergusson e Horwood (1998), em uma investigação com 1265 adolescentes da Nova Zelândia sobre exposição à violência conjugal e qualidade de ajustamento pessoal na adolescência, encontraram que as crianças que haviam sido expostas a altos níveis de violência parental apresentavam maior risco de sintomas de ansiedade, desordens de conduta, envolvimento com crimes e problemas com álcool.

Entretanto, De Antoni e Koller (2000) consideram que, mesmo sob circunstancias adversas, adolescentes podem ter uma percepção crítica sobre o impacto da violência intra-familiar. Numa investigação com adolescentes femininas institucionalizadas sobre suas próprias visões acerca da noção de família, as pesquisadoras identificaram o desejo de estabelecimento de projetos familiares diversos aos vividos na sua própria família num esforço de constituir relações familiares distintas. Embora as situações de violência familiar vividas pelas adolescentes fossem indicadores de risco grave, muitas vezes mascaradas por uma visão familiar idealizada, esse aspecto coloca uma questão importante referente à percepção do adolescente sobre sua experiência passada e sua motivação para um engajamento em relações afetivas diversas.

\section{Modelos Processuais}

Ainda que a importância dos estudos iniciais sobre as relações familiares tenha sido evidenciada nas associações encontradas entre conflito conjugal e características do ajustamento infantil, a diversidade de situações (contexto) e os diferentes fatores mediadores do impacto sobre o desenvolvimento infantil apontaram a necessidade de se organizarem modelos processuais mais complexos sobre os fenômenos em questão.

\section{Modelo cognitivo-contextual}

Grych e Fincham (1990) consideram que o impacto da exposição ao conflito conjugal depende do contexto maior onde ocorrem os episódios de conflito, da capacidade cognitiva de interpretação dos acontecimentos e das estratégias de enfrentamento utilizadas pela criança. Desta forma, propõem o modelo cognitivo-contextual como uma tentativa explanatória e compreensiva dos diversos componentes atuantes na relação criança e família, considerando que as conseqüências do conflito conjugal no desenvolvimento da criança e do adolescente são mediadas pelas capacidades de compreensão e avaliação das situações parentais de discórdia. Portanto, características específicas, como idade, sexo e processos cognitivos envolvidos na avaliação da situação (experiência passada, capacidade de compreensão, por exemplo) irão determinar os efeitos da exposição à conflitiva conjugal. Nesse modelo, o aspecto afetivo resultaria da avaliação processual cognitiva da situação de discórdia parental por parte da criança. Primeiramente, a exposição ao conflito gera um estado afetivo de ansiedade/medo na criança, a qual utiliza estratégias de enfrentamento para lidar com a situação, baseadas nas suas características cognitivas e atribuições causais. Dependendo das características do conflito (intensidade, conteúdo, duração e resolução) e da faixa etária da criança, diferentes conseqüências ocorrerão no processo de desenvolvimento. A criança pode oscilar entre atribuir a si mesma a responsabilidade pelo conflito ou atribuir aos pais. Essas situações geram estados afetivos de culpa e de vergonha ou de raiva dirigida a um dos pais ou a ambos. Além dos processos cognitivos primários de avaliação do conflito como dos processos secundários de atribuições e estabelecimento de estratégias de enfrentamento, outros aspectos também interferem no impacto na criança. Processos distais ou situações ao longo do desenvolvimento (experiência prévia com conflitos, percepção da criança do clima familiar, temperamento e gênero) e processos proximais (situações mais transitórias e imediatas de avaliação da situação, correspondendo às expectativas frente ao evento e ao estado afetivo ou humor da criança no momento) irão influenciar as conseqüências do conflito.

Em síntese, atribuições e estratégias de enfrentamento inadequadas frente ao conflito conjugal podem colocar a 
criança em situação de vulnerabilidade emocional, já que os estados afetivos de ansiedade, de frustração e de raiva despertados pela exposição ao conflito não são adequadamente processados. Algumas situações podem levar ao desenvolvimento de uma atitude de auto - recriminação, afeto deprimido, baixa auto-estima ou raiva que, ao longo do desenvolvimento, acabam interferindo no processo de amadurecimento psicossocial da criança.

\section{Modelo segurança-emocional}

Davies e Cummings (1994) também desenvolveram um modelo processual sobre o impacto do conflito conjugal no desenvolvimento infantil. Utilizando-se de uma análise multidimensional dos diferentes componentes inter-relacionados na determinação do impacto do conflito conjugal na criança e no adolescente, os autores também consideram o contexto onde ocorre o conflito, as características da criança, a experiência passada, o nível de estresse e as estratégias de enfrentamento como elementos principais atuantes na forma como a criança processará a experiência. Esses elementos se inter-relacionam de uma forma dinâmica, ao longo do tempo, para influenciar o processo de desenvolvimento psicossocial da criança e do adolescente. Entretanto, mesmo a partir desta visão multidimensional, os autores enfatizam que a ação desses diferentes elementos de influência se fundamenta num aspecto básico do desenvolvimento psicológico que é a experiência afetiva de segurança emocional.

As emoções, partindo de uma perspectiva funcionalista, servem como um monitor do estado psicológico interno e da experiência de segurança emocional individual, orientando o comportamento no sentido de manter um estado de regulação emocional, quando se está em face de uma situação estressante. A experiência de segurança emocional se desenvolve a partir das representações de apego estabelecidas ao longo do relacionamento da criança com as figuras cuidadoras, em situações onde predominaram elementos de afeto, apoio, compreensão e suporte emocional. Entretanto, também no desenvolvimento posterior, a experiência de segurança emocional é determinada pela qualidade da relação parental, ainda que influenciada pelas vivências de apego iniciais. Isto é, a noção de segurança emocional, ainda que ligada às experiências de apego iniciais, seria influenciada pelas trocas posteriores ao longo do desenvolvimento com as figuras parentais.

O impacto do conflito conjugal sobre a experiência de segurança emocional ocorre na medida em que as situações de discórdia geram estados de ansiedade na criança, medo e insegurança (Davies \& Cummings, 1994). A exposição ao conflito conjugal teria o papel de interferir na qualidade dessas representações familiares, no momento em que se associam experiências de estresse ligadas às figuras parentais, fonte das vivências afetivas de estabilidade da criança. Em termos gerais, o construto segurança emocional corresponde a um processo dinâmico envolvendo subsistemas regulatórios compostos pelos componentes (a) de regulação emocional, ou a capacidade da criança em reduzir, aumentar e manter seu estado emocional quan- do frente a conflitos, (b) de representações das relações familiares, ou o significado dos acontecimentos na família em relação à experiência de segurança emocional e (c) de regulação da exposição ao afeto, ou dos comportamentos regulatórios que controlam a exposição da criança aos afetos resultantes das discórdias familiares. Desta maneira, quando face às situações estressantes envolvendo discórdias e conflitos familiares, a criança reage ao afeto negativo e à ansiedade, esforçando-se por criar mecanismos mediadores de controle, tanto em nível de seus próprios estados de ansiedade interna, como também do controle do comportamento dos próprios adultos envolvidos na disputa. Assim, o estado emocional negativo, ativado pela exposição ao conflito conjugal, perturba o sentido de segurança emocional interna, fazendo com que a criança procure acionar mecanismos que restabeleçam a segurança emocional. Podem ocorrer tentativas de controle da disputa parental, por meio de interferência direta da criança ou de condutas de mau comportamento, de agressividade ou de choro (Smith, Berthelsen \& O'Connor, 1997).

A capacidade de regulação emocional é determinante da experiência da criança face ao conflito. Portanto, os efeitos negativos da exposição não resultam diretamente das características menos ou mais intensas do conflito parental, mas, sim, da percepção de ameaça à capacidade de manutenção da segurança emocional interna da criança, alterada pelo conflito.

\section{Considerações Finais - Contribuições à Pesquisa em Psicopatologia do Desenvolvimento}

A revisão da literatura discutida neste trabalho indicou que o campo das relações familiares é uma área de investigação fundamental para a compreensão do desenvolvimento psicológico. Nesse aspecto, a contribuição específica das relações familiares envolvendo situações de conflito conjugal evidenciou-se como um tópico de investigação importante nos estudos sobre os distúrbios no desenvolvimento da criança e do adolescente. Até o momento, as pesquisas apontam para o impacto negativo do conflito conjugal no desenvolvimento psicológico, principalmente daquelas situações familiares envolvendo violência física e verbal entre o casal. Os resultados dos trabalhos indicam que os conflitos conjugais estão relacionados a distúrbios em diferentes aspectos do desenvolvimento da criança e do adolescente, tais como nas áreas emocional, cognitiva e social.

Inicialmente, embora as situações de conflito e adversidade familiar estivessem claramente implicadas na ocorrência de distúrbios no desenvolvimento, foi fundamental a especificação dos diferentes aspectos do construto conflito familiar para o avanço da compreensão da dinâmica familiar. A partir da análise mais precisa das diferentes situações de conflito conjugal, verificou-se que os efeitos negativos das interações conjugais estavam associados a determinadas características dos processos envolvendo o conflito. Isto é, constatou-se que a associação entre exposição aos conflitos conjugais e o desenvolvimento infantil 
dependiam da freqüência, da intensidade, do conteúdo e da forma de resolução dos conflitos. Além disto, as definições mais precisas sobre as características do conflito conjugal permitiram uma abordagem metodológica mais complexa dos estudos sobre as diferentes interações conjugais nas resoluções de conflito. Verificou-se que os diferentes padrões de conflito conjugal refletiam não somente as características da interação entre o casal, mas também eram influenciados por questões mais amplas da vida relacional familiar e afetavam de forma diferenciada o desenvolvimento infantil. Passou-se, então, de uma análise unidimensional do conflito familiar para uma compreensão multidimensional dos processos familiares envolvidos nos conflitos conjugais e nas conseqüências para o desenvolvimento infantil.

Como conseqüência, a análise multidimensional dos diversos fatores contextuais, familiares e individuais associados aos efeitos da exposição ao conflito conjugal, levou a construção de modelos processuais das associações entre as variáveis atuantes ao longo do desenvolvimento psicológico. O modelo cognitivo-contextual enfatiza o contexto maior onde ocorrem os episódios de conflito, a capacidade cognitiva da criança de interpretação dos fatos e suas estratégias de enfrentamento, enquanto que o modelo de segurança emocional destaca a capacidade da criança de manutenção da regulação emocional. Mesmo que enfatizando a ação de alguns aspectos de maneira mais específica, tal como no modelo cognitivo-contextual ou no modelo de segurança emocional, as interações processuais entre os fatores são similares nos modelos propostos, visto que ambos identificam a sobreposição dinâmica das ações dos diversos componentes do sistema familiar. Tanto considerando os efeitos da exposição direta ao conflito conjugal, como do efeito de fatores mediadores, os modelos se equiparam na abrangência das propostas.

Cummings e Davies (2002) propõem que as pesquisas na área devam se orientar por uma aproximação abrangente dos fenômenos atuantes no desenvolvimento infantil, fundamentadas na noção de que comportamentos específicos são influenciados por diversos sistemas, incluindo aqueles próximos à esfera de vida imediata da criança até aqueles mais distais. Da mesma forma, essas influências afetam o desenvolvimento conforme o período evolutivo e a capacidade de resposta da criança. Portanto, ao se falar em distúrbios do desenvolvimento, deve-se partir de uma concepção de psicopatologia que compreenda o distúrbio como uma resposta complexa da criança a determinada situação. A essa noção dinâmica de análise e compreensão dos comportamentos infantis, Cummings e Davies denominam modelo de pesquisa orientada ao processo, isto é, a direção explicativa se orienta pela noção da complexidade e diversidade dos fatores em questão e por suas ações dinâmicas. A aproximação ao estudo dos desajustes e dificuldades de adaptação, no campo da psicopatologia do desenvolvimento, orientar-se-ia por uma abrangência complexa dos fenômenos, principalmente em relação aos efeitos da dinâmica conjugal no desenvolvimento infantil. Finalmente, Cummings e Davies (2002) salientam que grande parte das pesquisas estuda grupos familiares de procedência anglo-saxônica e apontam a necessidade de ampliação das investigações para grupos de diferentes culturas. Considerando-se a complexidade da sociedade brasileira e a relevância do tema, é importante e necessário o desenvolvimento de trabalhos e pesquisas que reflitam as características nacionais, a fim de que se investiguem os aspectos peculiares do contexto familiar e das formas de conflito conjugal em relação às influências culturais específicas. Ainda que os fatores identificados como associados ao conflito conjugal e às conseqüências da exposição às interações parentais adversas reflitam características do funcionamento familiar relativamente similares em diversos grupos sociais, eles estão inseridos num contexto cultural mais amplo. A identificação destes aspectos é fundamental para uma visão mais abrangente das interações familiares em contextos diversos e para a análise do impacto destas interações no desenvolvimento da criança e do adolescente.

Como conclusão, espera-se que esta discussão dos trabalhos sobre a questão dos efeitos do conflito conjugal na psicopatologia infantil, além de apresentar os resultados das pesquisas sobre o tema, forneça elementos de aproximação compreensiva dos fenômenos psicológicos à luz de uma abordagem baseada no modelo processual da complexidade dinâmica dos fatores. E, igualmente, estimulando o desenvolvimento de trabalhos contextualizados nesta área.

\section{Referências}

Belsky, J. (1984). The determinants of parenting: A process model. Child Development, 55, 83-96.

Coyne J. C., Thompson, R., \& Palmer, S. C. (2002). Marital quality, coping with conflict, marital complaints, and affection in couples with a depressed wife. Journal of Family Psychology, $16,26-37$

Cummings, E. M. (1995). Security, emotionality, and parental depression: A commentary. Developmental Psychology, 31, 425427.

Cummings, E. M. (1998). Children exposed to marital conflict and violence: Conceptual and theoretical directions. In G. Holden, B. Geffner \& E. Jouriles (Eds.), Children exposed to marital violence: Theory, research, and applied issues (pp. 21-53). Washington, DC: American Psychological Association.

Cummings, E. M., \& Davies, P. T. (1994). Maternal depression and child development. Journal-of-Child-Psychology-and-Psychiatryand-Allied-Disciplines, 35, 73-112.

Cummings, E. M., \& Davies, P. T. (2002). Effects of marital conflict on children: Recent advances and emerging themes in process oriented-research. Journal of Child Psychology and Psychiatry, 43, 31-63

Cummings, E. M., \& O’Reilly, A. (1997). Fathers in family context: Effects of marital quality on child adjustment. In M. E. Lamb (Ed.), The role of the father in child development (pp. 196-221). New York: John Wiley \& Sons.

Dadds, M. R., Sanders, M. R., Morrison, M., \& Rebgetz, M. (1992). Childhood depression and conduct disorder: II. An analysis of family interaction patterns in the home. Journal of Abnormal Psychology, 10, 505-513. 
Davies, P., \& Cummings, E. M. (1994). Marital conflict and child adjustment: An emotional security hypothesis. Psychological Bulletin, 116, 387-411.

De Antoni, C., \& Koller, S. H. (2000). A visão de família entre as adolescentes que sofreram violência intrafamiliar. Estudos de Psicologia, 2, 347-381.

Downey, G., \& Coyne, J. C. (1990). Children of depressed parents: An integrative review. Psychological Bulletin, 108, 50-76.

El-Sheikh, M., \& Harger, J. (2001). Appraisals of marital conflict and children's adjustment, health, and physio-logical reactivity. Developmental Psychology, 37, 875-885.

Emery, R. E., \& O'Leary, K. D. (1982). Children's perceptions of marital discord and behavior problems of boys and girls. Journal of Abnormal Child Psychology, 12, 411-420.

Fantuzzo, J. W., DePaola, L. M., Lambert, L., Martino, T., Anderson, G., \& Sutton, S. (1991). Effects of interparental violence on the psychological adjustment and competencies of young children. Journal of Consulting and Clinical Psychology, 59, 258-265.

Fergusson, D. M., \& Horwood, L. J. (1998). Exposure to interparental violence in childhood and psychological adjustment in young adul thood. Child Abuse \& Neglect, 22, 339357

Fincham, F. D. (1994). Understanding the association between marital conflict and child adjustment. Journal of Family Psychology, 8, 123-127.

Fincham, F. D. (2003). Marital conflict: Correlates, structure and context. Current Directions in Psychological Science, 12, 2327.

Fonagy, P., Target, M., Steele, M., \& Steele, H. (1997). The development of violence and crime as it relates to security of attachment. In J. Osowsky (Ed.), Children in a violent society (pp. 150-177). New York: Guildord Press.

Grych J. H., \& Fincham, F. D. (1990). Marital conflict and children's adjustment: A cognitive-contextual framework Psychological Bulletin, 108, 267-290.

Hetherington, E. M., \& Stanley-Hagan, M. (1999). The adjustment of children with divorced parents: A risk and resilience perspective. Journal of Child Psychology and Psychiatry, 1,129-140.

Holden, G. W., Geffner, R., \& Jourilles, E. N. (Eds.). (1998). Children exposed to marital violence: Theory, research, and applied issues. Washington, DC: American Psychological Association.

Jenkins, J. M., \& Smith, M. A. (1991). Marital disharmony and children's behavioral problems: Aspects of a poor marriage that affect children adversely. Journal of Child Psychology and Psychiatry, 32, 793-810

Johnston, J. R., Gonzalez, R., \& Campbell, L. E. (1987). Ongoing postdivorce conflict and child disturbance. Journal of Abnormal Child Psychology, 15, 497-509.

Jouriles, E. N., Murphy, C. M., \& O'Leary, K. D. (1989). Interspousal aggression, marital discord, and child problems Journal of Consulting and Clinical Psychology, 57, 453-455.

Katz, L. F., \& Gottman, J. M. (1993) Patterns of marital conflict predict children's internalizing and externalizing behaviors, Developmental Psychology, 29, 940-950.

Lisboa, C., Koller, S. H., Ribas, F. F., Bitencourt, K., Oliveira, L., Porciuncula, L. P., \& De Marchi, R. B. (2002). Estratégias de Coping de crianças vítimas e não vítimas de violência doméstica. Psicologia: Reflexão e Crítica, 15, 345-362

McCloskey, L. A., Figueredo, A. J., \& Koss, M. P. (1995). The effects of systemic family violence on children's mental health, Child Development, 66, 1239-61.
Oliveira, E. A., Marin, A. H., Pires, F. B., Frizzo, G. B., Ravanello, T., \& Rossato, C. (2002). Estilos parentais autoritário e democrático-recíproco intergeracionais, conflito conjugal e comportamentos de externalização e internalização. Psicologia: Reflexão e Crítica, 15, 1-11.

Ross, S. (1996). Risk of physical abuse to children of spouse abusing parents. Child Abuse \& Neglect, 20, 589-598.

Santos, L. V., \& Costa, L. F. (2004). Avaliação da dinâmica conjugal violenta e suas repercussões sobre os filhos. Psicologia: Teoria e Prática, 6(1), 59-72.

Smith, J., Berthelsen, D., \& O’Connor, I. (1997). Child adjustment in high conflict homes. Child: care, health and development, 23, 113-133.

Wamboldt, M. Z, \& Wamboldt, F. S. (2000). Role of the family in the onset and outcome of childhood disorders: Selected research findings. Journal of American Academy of Child Adolescent Psychiatry, 39, 1212-1219.

Wolfe, D. A. (1999). Child abuse: Implications for child development and psychopathology. Thousand Oaks, CA: Sage.

Zavaschi, M. L, Benetti, S. P., Polanczyk, G. V., Solés, N., \& Sanchotene, M. L. (2002). Adolescents exposed to physical violence in the community: A survey in Brazilian public schools. Revista Panamericana de Salud Publica, 12, 327-32.

Zeanah, C. H., \& Scheeringa, M. S. (1997). The experience and effects of violence in infancy. In J. Osowsky (Ed.), Children in a violent society (pp. 97-123). New York: Guilford Press.
Recebido: 22/09/2004 $I^{a}$ revisão: $30 / 03 / 2004$ $2^{a}$ revisão: 20/07/2005 Aceite final: 16/09/2005 